\title{
Severe hypoglycaemia and cardiovascular disease: systematic review and meta-analysis with bias analysis
}

\author{
(@) $\mathbb{Q} \Theta$ OPEN ACCESS
}

\author{
Atsushi Goto senior researcher ${ }^{12}$, Onyebuchi A Arah professor ${ }^{34}$, Maki Goto researcher ${ }^{12}$, Yasuo \\ Terauchi professor $^{2}$, Mitsuhiko Noda director ${ }^{1}$
}

'Department of Diabetes Research, Diabetes Research Center, National Center for Global Health and Medicine, 1-21-1 Toyama, Shinjuku-ku, Tokyo 162-8655, Japan; '2Department of Endocrinology and Metabolism, Yokohama City University Graduate School of Medicine, Yokohama, Japan; ${ }^{3}$ Department of Epidemiology, UCLA Fielding School of Public Health, Los Angeles, CA, USA; ${ }^{4}$ Department of Public Health, Academic Medical Center, University of Amsterdam, Amsterdam, Netherlands

\begin{abstract}
Objectives To provide a systematic and quantitative summary of the association between severe hypoglycaemia and risk of cardiovascular disease in people with type 2 diabetes and to examine the sensitivity of the association to possible uncontrolled confounding by unmeasured comorbid severe illness using a bias analysis.

Design Meta-analysis of observational studies.

Data sources Medline, Embase, the Cochrane Library, and Web of Science databases were searched to February 2013, without any language restrictions.

Eligibility criteria Two independent reviewers selected cohort studies that evaluated the association of severe hypoglycaemia with cardiovascular events in people with type 2 diabetes; we excluded studies from acute hospital settings. We extracted descriptive and quantitative data.
\end{abstract}

Results Of 3443 citations screened, six eligible studies with 903510 participants were identified. In the conventional random effects meta-analysis, severe hypoglycaemia was strongly associated with a higher risk of cardiovascular disease (relative risk $2.05,95 \%$ confidence interval 1.74 to $2.42 ; \mathrm{P}<0.001)$. The excess fraction of cardiovascular disease incidence that was attributable to severe hypoglycaemia (the population attributable fraction) was $1.56 \%$ (95\% confidence interval $1.32 \%$ to $1.81 \% ; P<0.001)$. Although moderate heterogeneity across the studies was suggested $\left(I^{2}=73.1 \% ; P=0.002\right.$ for heterogeneity), most subgroups showed similar results in stratified analyses. The bias analysis indicated that comorbid severe illness alone may not explain the association between hypoglycaemia and cardiovascular disease; to explain this association, comorbid severe illness would have had to be extremely strongly associated with both severe hypoglycaemia and cardiovascular disease.

Conclusion Our findings suggest that severe hypoglycaemia is associated with a higher risk of cardiovascular disease; they also support the notion that avoiding severe hypoglycaemia may be important to prevent cardiovascular disease in people with type 2 diabetes.

Correspondence to: M Noda mnoda@hosp.ncgm.go.jp

Extra material supplied by the author (see http://www.bmj.com/content/347/bmj.f4533?tab=related\#webextra) Supplementary information

Video on bmj.com (see also http://bmj.com/video)

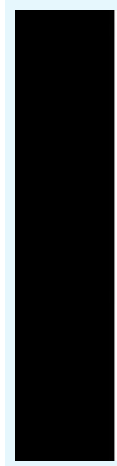

ACCORD: Total mortality

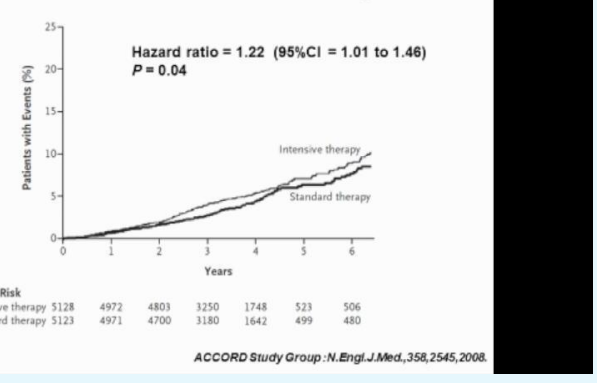

Video abstract 


\section{Introduction}

Severe hypoglycaemia is a potential risk factor for cardiovascular disease in people with type 2 diabetes. ${ }^{12}$ Meta-analyses of recent clinical trials indicated that intensive glucose control was associated with a reduced risk of non-fatal myocardial infarction in people with type 2 diabetes. ${ }^{34}$

Individually, however, these recent clinical trials have failed to show a beneficial effect of intensive glucose control on overall cardiovascular disease events, ${ }^{5-7}$ despite earlier observational studies indicating a strong positive association between diabetes or hyperglycaemia and risk of cardiovascular disease. ${ }^{8-10}$ If severe hypoglycaemia induces cardiovascular disease events, it may also dilute the potential benefit of intensive glucose control on such events because intensive glucose control increases the risk of severe hypoglycaemia. ${ }^{3}$ This is biologically plausible because severe hypoglycaemia has acute effects on sympathoadrenal activation, ${ }^{11}$ inflammation, ${ }^{12}$ and endothelial function, ${ }^{13}$ all of which have potential adverse cardiovascular effects. In addition, cardiac ischaemia or fatal arrhythmia during hypoglycaemia may be responsible for the increased risk of cardiovascular disease among patients with severe hypoglycaemia..$^{14} 15$

Although observational studies have reported a positive association between severe hypoglycaemia and risk of cardiovascular disease, ${ }^{12}$ this association remains controversial. Some have suggested that severe hypoglycaemia may be a marker of vulnerability to cardiovascular disease events ${ }^{1}$ because the risk of hypoglycaemia is increased in patients with comorbid severe illnesses (for example, renal disease, liver disease, cognitive decline, and terminal cancer) that are risk factors for serious adverse health outcomes. Thus comorbid severe illnesses may confound the association between hypoglycaemia and cardiovascular disease. Randomisation of patients to hypoglycaemic and non-hypoglycaemic groups is not feasible; however, a bias analysis may help to elucidate the impact of a comorbid severe illness on the association between severe hypoglycaemia and cardiovascular disease.

We conducted a systematic review and meta-analysis to evaluate if severe hypoglycaemia is associated with risk of cardiovascular disease, and if confounding from an unmeasured comorbid severe illness accounts for the reported association between severe hypoglycaemia and cardiovascular disease, using a bias analysis.

\section{Methods}

We searched Medline, Embase, the Cochrane library, and Web of Science to February 2013, without any language restrictions (initial search on 5 September 2012; search updated 11 December 2012 and 27 February 2013); a beginning timeframe was not set. The Medline search terms were ("diabetes mellitus, type 2"[MeSH Terms] OR "type 2 diabetes mellitus"[All Fields]) AND ("hypoglycemia"[MeSH Terms] OR "hypoglycemia"[All Fields] OR "hypoglycaemia"[All Fields]) AND ("cardiovascular diseases"[MeSH Terms] OR "cardiovascular diseases"[All Fields] OR ("cardiovascular"[All Fields] AND “diseases"[All Fields]) OR ("cardiovascular"[All Fields] AND "disease"[All Fields])). We adapted this search strategy for searches of Embase (using Emtree terms), the Cochrane library, and the Web of Science (see supplementary text A). We also searched the references of relevant studies. Although this meta-analysis did not have a registered review protocol, we followed the recommendations of the Meta-analysis of Observational Studies in Epidemiology (MOOSE) Group. ${ }^{16}$
The researchers are experienced with systematic reviews of the literature..$^{17-22}$

\section{Study selection}

Two independent investigators ( $\mathrm{AG}$ and $\mathrm{MG}$ ) read all retrieved abstracts and titles. The inclusion criteria were: a cohort study of people with type 2 diabetes, cardiovascular disease reported as the study outcome, and provision of an association between hypoglycaemia and cardiovascular disease. We defined cohort studies as those that prospectively identified a group of people, assessed exposures of interest, and followed them for incidence of outcome events (that is, prospective cohort studies) or those that used existing data records to retrospectively identify a group of people and assess exposures of interest and incidence of outcome events (that is, retrospective cohort studies). We included randomised controlled trials as long as an observational analysis of the association between hypoglycaemia and cardiovascular disease was available. Studies in acute hospital settings were excluded. Full texts of potentially eligible studies were retrieved and screened to determine their eligibility; discrepancies between the reviewers' selections were resolved by discussion.

\section{Data extraction}

We extracted information on study characteristics (authors, design, year of publication, sample size, duration of follow-up); participants' characteristics (age, sex, duration of diabetes, cardiovascular disease history, insulin use, body mass index, smoking status, low density cholesterol level, systolic blood pressure, glycated haemoglobin $\left(\mathrm{HbA}_{1 \mathrm{c}}\right)$ level, fasting plasma glucose level); exposure assessment; outcome assessment; analysis strategy; and multivariable adjusted relative risks. If the appropriate information was missing, we requested this from the investigators. Two investigators (AG and $\mathrm{MG}$ ) extracted data independently and discrepancies were resolved by discussion.

\section{Quality assessment}

To assess study quality, ${ }^{23}$ we evaluated each study for its design, sources of participants, follow-up time, exposure assessment, outcome assessment, and the extent of adjustment for potential confounders. We chose not to use a scoring system to formally rate study quality because such scoring submerges important information by combining disparate study characteristics into one score. ${ }^{23}$

\section{Statistical analysis}

We used relative risk as a measure of effect estimates. One study used logistic regression models to estimate odds ratios ${ }^{24}$; the others used Cox proportional hazard models to estimate hazard ratios. ${ }^{1-27}$ Because the risk of cardiovascular disease incidence was low, we used both the hazard ratios and the odds ratios to approximate the relative risk. ${ }^{23} \mathrm{We}$ assessed potential publication bias using funnel plots, Begg's test, ${ }^{28}$ and Egger's test. ${ }^{29} \mathrm{We}$ performed data synthesis using a conventional random effects model ${ }^{30}$ which ignores possible confounding by comorbid severe illness. We assessed statistical heterogeneity of relative risks across studies using the Cochrane's Q test ${ }^{31}$ and $\mathrm{I}^{2}$ statistics. ${ }^{32}$ We considered low, moderate, and high degrees of heterogeneity to be $\mathrm{I}^{2}$ values of below $25 \%, 25-75 \%$, and above $75 \%$, respectively. We also performed stratified analyses according to study design (that is, prospective studies ${ }^{12}$ versus retrospective studies ${ }^{24-27}$ ), study location (United States ${ }^{2-25}$ versus non-United States ${ }^{1-27}$ ), sex (mainly men ${ }^{25}$ versus both sexes ${ }^{1-27}$ ), 
duration of follow-up ( $>1$ year $^{1-27}$ versus $\leq 1$ year $^{24}$ ), insulin use (included $^{1-27}$ versus excluded ${ }^{26}$ ), adjustment for race and dyslipidaemia (yes ${ }^{2-27}$ versus no ${ }^{1}$ ), adjustment for smoking status (yes ${ }^{1-25}$ versus $\mathrm{no}^{24-27}$ ), and adjustment for body mass index $\left(\right.$ yes $^{125}$ versus $n^{2-27}$ ). We computed $\mathrm{P}$ values for comparisons between subgroups using the $\chi^{2}$ test with 1 degree of freedom.

The potential impact of uncontrolled confounding by unmeasured severe comorbid illnesses was explored. Since data have not been published regarding the distribution of comorbid severe illnesses or their effect on the risk of cardiovascular disease in people with type 2 diabetes, we assigned a wide range of plausible bias values. We then computed the adjusted relative risks and $95 \%$ confidence intervals, externally adjusted for the unmeasured comorbid severe illnesses. Specifically, we conducted a bias analysis by dividing the observed (preadjusted) relative risk of each study $(i=1,2$, etc) by a bias factor, which was interpreted as the degree of bias due to failure to adjust for severe comorbid illness, using the following formula ${ }^{23}{ }^{33}$ : bias factor $i=\mathrm{RR}_{i \text { preadjusted }} / \mathrm{RR}_{i \text { adjusted }}=\left(\mathrm{RR}_{i \mathrm{DZ}} \mathrm{P}_{i \mathrm{Z1}}+1-\mathrm{P}_{i \mathrm{Z1}}\right) /\left(\mathrm{RR}_{i \mathrm{DZ}} \mathrm{P}_{i \mathrm{ZO}}+1-\mathrm{P}_{i}\right.$ ${ }_{\text {z0 }}$ ) where $\mathrm{RR}_{i \text { preadjusted }}$ is the observed relative risk; $\mathrm{RR}_{i \text { adjusted }}$ is the relative risk adjusted for the unmeasured comorbid severe illness (Z); $\mathrm{RR}_{i \mathrm{DZ}}$ is the relative risk relating the unmeasured comorbid severe illness and cardiovascular disease (D), given hypoglycaemia; $\mathrm{P}_{i \mathrm{Zl}}$ is the prevalence of the unmeasured comorbid severe illness in the hypoglycaemic group; and $\mathrm{P}_{i z 0}$ is the prevalence of the unmeasured comorbid severe illness in the non-hypoglycaemic group in each study $\left(i=1,2\right.$, etc) ${ }^{23}$ The bias adjusted relative risk $\left(\mathrm{RR}_{i \text { adjusted }}\right)$, which was our target, was obtained by dividing the preadjusted relative risk $\left(\mathrm{RR}_{i \text { preadjusted }}\right)$ by the bias factor from the formula above. Although the degree of residual confounding may have differed across studies, we assigned the same bias factor to all studies for simplicity. Assuming that the standard errors of the bias adjusted relative risks were not affected by unmeasured confounding, ${ }^{34}{ }^{35}$ we estimated the standard errors of the logarithm of bias adjusted relative risks by the usual likelihood procedures. The bias adjusted relative risks were pooled using a random effects model. ${ }^{30} \mathrm{We}$ repeated the above adjustment process, using wide ranges of values, for the proportions of patients with comorbid severe illness and the effects of the comorbid severe illness on cardiovascular disease.

We also estimated the excess fraction of cardiovascular disease incidence that was attributable to severe hypoglycaemia (the population attributable fraction), under the assumption that the observed association of severe hypoglycaemia with cardiovascular disease risk represented a causal effect. To estimate the population attributable fraction $(\mathrm{PAF})$, we used the following formula: $\mathrm{PAF}=p_{c}(\mathrm{RR}-1) / \mathrm{RR}$, where $p_{c}$ is the proportion of exposure prevalence among patients who developed cardiovascular disease. ${ }^{23}$ We estimated $p_{c}$ using the frequency of severe hypoglycaemia seen in patients who developed cardiovascular disease in the Action in Diabetes and Vascular Disease: Preterax and Diamicron Modified Release Controlled Evaluation (ADVANCE) trial; only this study provided the frequency in question $(35 / 1147=3.1 \%)$. We estimated the confidence interval for the population attributable fraction using the Monte Carlo method. ${ }^{36}$ The analyses were performed using SAS version 9.3 and Stata version 12.1.

\section{Results}

Our initial search identified 3443 citations. Based on the titles and abstracts, 56 citations were considered potentially eligible and we evaluated the full texts of these 56 citations. A total of 50 studies were subsequently excluded; three were performed in acute hospital settings, one was a design paper, 34 did not report an association between hypoglycaemia and cardiovascular disease, and 12 were reviews or abstracts from meetings. Of the three excluded studies performed in acute hospital settings, the Diabetes Mellitus Insulin-Glucose Infusion in Acute Myocardial Infarction 2 (DIGAMI-2) study showed an association between hypoglycaemia and cardiovascular disease, but its study participants were patients admitted to participating coronary care units for suspected acute myocardial infarction. ${ }^{37}$ Thus, the DIGAMI-2 study was not included in this meta-analysis. We did not include the Action to Control Cardiovascular Risk in Diabetes (ACCORD) trial ${ }^{38}$ or the study by McCoy et $\mathrm{al}^{39}$; these studies provided relative risks for mortality associated with hypoglycaemia, but the relative risk for cardiovascular disease associated with severe hypoglycaemia was not available. Of the meeting abstracts identified through our search, two satisfied our eligibility criteria ${ }^{40}{ }^{41}$; the full text articles were retrieved ${ }^{25} 27$ and included in our meta-analysis. Therefore, six studies were eventually included in the meta-analysis (fig $1 \Downarrow$ ). ${ }^{1-27}$

\section{Study characteristics and quality assessment}

Tables $1 \Downarrow$ and $2 \Downarrow$ show the characteristics of the studies included in the meta-analysis. Two studies (the ADVANCE ${ }^{1}$ study and the Veterans Affairs Diabetes Trial [VADT] $]^{2}$ ) were secondary analyses of randomised clinical trials, and the other four studies (Johnston et al, ${ }^{24}$ Zhao et al, ${ }^{25}$ Rathmann et al, ${ }^{26}$ and Hsu et $\mathrm{al}^{27}$ ) were based on administrative databases. The number of participants ranged from 1522 to 860845 , with a mean age range of 60-67 years and a mean duration of diabetes of 3.2-11.5 years; the follow-up period ranged from 1 to 5.6 years. The VADT, ${ }^{2}$ Johnston et $\mathrm{al}^{24}$ and Zhao et $\mathrm{al}^{25}$ studies were conducted in the United States; the ADVANCE study was done in Europe, Asia, Australia/New Zealand, and Canada ${ }^{1}$; Rathmann et $\mathrm{al}^{26}$ in Germany; and Hsu et $\mathrm{al}^{27}$ in Taiwan. The quality of the secondary analyses of randomised controlled trials (the ADVANCE study and VADT) $)^{12}$ was generally high. The detailed quality assessment is described in supplementary text B and table A). All of the included studies adjusted for age, sex, history of cardiovascular disease, history of microvascular complications or its surrogate, baseline health status, and use of antihyperglycaemic agents. Other factors, such as race, dyslipidaemia, smoking status, and body mass index, were less consistently adjusted (table 2 and supplementary text). The impact of unmeasured comorbid severe illness was not assessed in these studies.

\section{Conventional random effects meta-analysis}

The six studies included 903510 participants, with 1 to 5.6 years of follow-up. During the follow-up period, $0.6 \%$ to $5.8 \%$ experienced severe hypoglycaemia. The conventional random effects meta-analysis, which ignores unmeasured confounding, indicated that severe hypoglycaemia was strongly associated with a higher risk of cardiovascular disease (relative risk 2.05, $95 \%$ confidence interval 1.74 to $2.42 ; \mathrm{P}<0.001$ ) (table $3 \Downarrow$ and fig $2 \Downarrow)$. Moderate heterogeneity among these studies was indicated $\left(\mathrm{I}^{2}=73.1 \% ; \mathrm{P}=0.002\right.$ for heterogeneity). There was little evidence of publication bias. The funnel plot did not indicate asymmetry; Begg's P value was 0.71 and Egger's bias coefficient was 1.49 (95\% confidence interval -1.50 to 4.47 ; $\mathrm{P}=0.24$ ) (see supplementary figure $\mathrm{A}$ ). We also estimated the population attributable fraction for cardiovascular disease associated with severe hypoglycaemia, assuming that the observed association between severe hypoglycaemia and cardiovascular disease reflected a causal effect of severe hypoglycaemia on risk of cardiovascular disease in people with 
type 2 diabetes. The excess fraction of cardiovascular disease incidence attributable to severe hypoglycaemia was $1.56 \%$ (95\% confidence interval $1.32 \%$ to $1.81 \% ; \mathrm{P}<0.001$ ).

\section{Stratified analysis}

To examine possible sources of heterogeneity across studies, we carried out stratified analyses according to study design, study location, sex, duration of follow-up, insulin use, adjustment for race and dyslipidaemia, adjustment for smoking status, and adjustment for body mass index (table 3). Stratified analysis according to study design did not indicate apparent heterogeneity. Subgroups by duration of follow-up and by adjustment for race and dyslipidaemia seemed to differ in the magnitude of relative risk estimates. In a stratified analysis according to duration of follow-up, the pooled relative risk from studies with a duration of follow-up of more than one year ${ }^{1-27}$ (that is, the pooled relative risk excluding the study by Johnston et al) was larger than the relative risk from the study by Johnston et $\mathrm{al}^{24}(2.16,95 \%$ confidence interval 1.77 to $2.64 v 1.79,1.69$ to $1.89 ; \mathrm{P}=0.07$ for interaction). In addition, the $\mathrm{ADVANCE}^{1}$ study did not adjust for race and dyslipidaemia, and it had larger a relative risk than the pooled relative risk from the other studies $^{2-27}(3.45,2.34$ to $5.08 v 1.93,1.70$ to $2.18 ; \mathrm{P}=0.005$ for interaction). However, stratification by these factors did not explain much of the heterogeneity in results, with $\mathrm{I}^{2}$ statistics moderate to high within each stratum.

\section{Random effects meta-analysis with bias analysis}

All studies showed a strong positive association between hypoglycaemia and cardiovascular disease (with point estimates of the relative risk ranging from 1.60 to 3.45 ). We performed a bias analysis to provide quantitative estimates, externally adjusted for comorbid severe illness (fig $3 \Downarrow$ and supplementary table B). The bias analysis indicated that comorbid severe illness, alone, may not explain the observed association between severe hypoglycaemia and cardiovascular disease. To explain the association, comorbid severe illness would have had to be extremely strongly associated with both severe hypoglycaemia and cardiovascular disease. For example, to account for the association, comorbid severe illness would have needed to be 10 times more prevalent in patients with severe hypoglycaemia than in those without severe hypoglycaemia, and would have to have had a relative risk of 10 .

\section{Discussion}

In this meta-analysis of 903510 people with type 2 diabetes, we observed a higher risk of cardiovascular disease among those with severe hypoglycaemia. The bias analysis indicated that the observed association between severe hypoglycaemia and cardiovascular disease may not be entirely due to confounding by severe comorbid illness. Although moderate heterogeneity across the studies was indicated, most subgroups showed similar results in stratified analyses. The strength of association observed in the $\mathrm{ADVANCE}^{1}$ study seemed to be greater than that in the other studies, possibly owing to differences in adjustment for potential confounding factors, study design, or study population; the strength of association in Johnston et al was lesser than that of the other studies, possibly because of its short duration of follow-up (one year). Given the concern that severe hypoglycaemia might be a risk factor for cardiovascular disease, avoiding severe hypoglycaemia may be important to prevent cardiovascular disease, and less stringent glycaemic targets may be considered for people with type 2 diabetes who are at high risk for hypoglycaemia. The findings provide additional support for the patient centred approach of the intervention for type 2 diabetes and glycaemic goal setting that aims to minimise the risk of hypoglycaemia, as recommended by the American Diabetes Association and the European Association for the Study of Diabetes. ${ }^{42}$

The association of severe hypoglycaemia with a higher risk of cardiovascular disease is biologically plausible. The sympathetic nervous response to severe hypoglycaemia increases catecholamine levels, resulting in acute adverse effects on the myocardium and the vascular system. ${ }^{11}$ The increase in catecholamine also leads to platelet activation, leucocyte mobilisation, and coagulation, ${ }^{12}$ which may trigger cardiovascular disease events. Inflammation and endothelial dysfunction are also induced by acute hypoglycaemia, ${ }^{13}$ and both play roles in the development of atherosclerosis. Furthermore, cardiac ischaemia or fatal arrhythmia during hypoglycaemia may lead to cardiovascular disease. ${ }^{14} 15$

\section{Strengths and limitations of this review}

The strengths of this study include the large sample size and the use of bias analysis. This type of analysis has the advantage of quantitatively accounting for possible sources of bias. ${ }^{43}$ Most published meta-analyses of observational studies do not explicitly and quantifiably evaluate those sources; instead, they are usually discussed in a more qualitative and abbreviated manner. However, when there are concerns that biases may be large, or when the observed associations seem precise, bias analyses can play an important role in drawing conclusions from these results. ${ }^{43}$ We encourage the use of bias analysis in meta-analyses of observational studies, especially when performing risk assessments or determining policy implications. This meta-analysis also has several limitations. Firstly, the analysis was confined to published studies, and individual patient data were not available. Although the funnel plot, Begg's test, or Egger's test did not indicate publication bias, the possibility of bias remains. For example, the ACCORD trial was not included in our meta-analysis because the relative risk for cardiovascular disease associated with severe hypoglycaemia was not available. If the findings from the ACCORD trial become available, the pooled estimates need to be updated. Secondly, several additional biases are likely to exist. Selection bias may exist, especially in studies using data extracted from electronic medical records,${ }^{25}$ claims based databases, ${ }^{24}{ }^{27}$ or primary care databases. ${ }^{26}$ Biases due to measurement error are also likely to be present, and may vary, in the included studies. The ICD-9-CM (international classification of diseases, ninth revision, clinical modification) or ICD-10 (international classification of diseases, 10th revision) coding may have led to outcome misclassification, biasing the results. Thirdly, there may also be other confounders, in addition to comorbid severe illness. A confounder, however, is required to have an effect substantially larger than the observed association and have a strong association with exposure, ${ }^{23}$ and comorbid severe illness is the only such factor currently suggested. Fourthly, the outcomes included heterogeneous manifestations of cardiovascular disease. Severe hypoglycaemia may have affected the risk of one or more, but not of all, of the subcategories of cardiovascular disease; this may have diluted the effect of severe hypoglycaemia on cardiovascular disease, as a single category, in this meta-analysis. Fifthly, all of the included studies examined the association between hypoglycaemia and cardiovascular disease in secondary analyses. Thus future work should include well designed, prospective cohort studies with the primary intention of evaluating the association between 
hypoglycaemia and risk of cardiovascular disease. Until then we believe that our results provide the best available evidence. Finally, our study was restricted to people with type 2 diabetes, which may limit the ability to generalise our findings to people with type 1 diabetes. Indeed, a recent study of relatively young people with type 1 diabetes found no association between severe hypoglycaemia and cardiovascular disease. ${ }^{44}$ Although severe hypoglycaemia occurs more commonly in people with type 1 diabetes than those with type 2 diabetes, cardiovascular disease events are relatively rare among young people with type 1 diabetes. ${ }^{44}$ Therefore, severe hypoglycaemia may have little impact on the risk of cardiovascular disease in these people.

\section{Implications}

Comorbid severe illness has been proposed to explain the positive association between severe hypoglycaemia and cardiovascular disease. ${ }^{1}$ However, our bias analysis indicated that confounding due to comorbid severe illness is unlikely to explain the association. To explain this association, the prevalence of comorbid severe illness would have needed to be unrealistically high among patients who experienced severe hypoglycaemia, and the strength of the association between severe illness and cardiovascular disease would have needed to be extremely strong. Given that the observed association was already adjusted for a wide range of covariates, uncontrolled, residual severe illness in the individual studies was unlikely to be unequally distributed in this extreme fashion. Therefore, the present findings suggest that the association between severe hypoglycaemia and cardiovascular disease may not be entirely due to confounding by comorbid severe illness.

New recommendations for antihyperglycaemic therapy in non-pregnant adults with type 2 diabetes have recently been proposed by the American Diabetes Association and the European Association for the Study of Diabetes ${ }^{42}$; these recommendations emphasise individualisation of glycaemic goals. Because intensive glucose control increases the risk of severe hypoglycaemia, ${ }^{3}$ the findings of this study add to the evidence supporting individualised glycaemic targets in people with type 2 diabetes. ${ }^{42}{ }^{45}$ Intensive therapy in the ACCORD trial was associated with a $22 \%$ increase in total mortality and a threefold increase in severe hypoglycaemia. ${ }^{5}$ Furthermore, a subgroup analysis of the ACCORD trial indicated that the increased mortality associated with intensive therapy was limited to those with a glycated haemoglobin $\left(\mathrm{HbA}_{1 \mathrm{c}}\right)$ level of $>8.0 \%,{ }^{5}$ suggesting that intensive glycaemic control may not be appropriate for those with poor glycaemic control. Our findings also support the notion that glucose lowering agents with a low propensity to induce hypoglycaemia (for example, metformin ${ }^{46}$ ) should be considered to avoid hypoglycaemia. Importantly, many severe hypoglycaemic episodes are preceded by a change in food intake ${ }^{47}$ suggesting that such episodes could be prevented by behavioural changes. In addition, particularly for patients treated with insulin, self monitoring of blood glucose can be useful in preventing hypoglycaemia. ${ }^{48}$

\section{Conclusions}

In summary, results from this meta-analysis suggest that severe hypoglycaemia is associated with approximately twice the risk of cardiovascular disease. Furthermore, a bias analysis indicates that the observed association between severe hypoglycaemia and cardiovascular disease may not be entirely due to confounding by comorbid severe illness. The findings support the notion that avoiding severe hypoglycaemia may be important to prevent cardiovascular disease in people with type 2 diabetes.
We thank Shao-Yuan Chuang, Wolfgang Rathmann, Yingnan Zhao, and Stephen Johnston for providing the data and the information for this meta-analysis.

Contributors: AG and MN designed the study. AG and MG independently searched the literature, selected the studies, and extracted the data. $A G$ and $O A A$ analysed and interpreted the data. $A G$ and $M G$ drafted the manuscript. OAA, YT, and MN contributed to the critical revision of the manuscript for important intellectual content. AG and NM are guarantors.

Funding: This work was funded by health sciences research grants (comprehensive research on life-style related diseases including cardiovascular diseases and diabetes mellitus H22-019 and H25-016) from the Ministry of Health, Labour and Welfare of Japan. OAA has been supported by Veni career grant No 916.96 .059 awarded by the Netherlands Organization for Scientific Research. The funders had no role in the study design, data collection, data analysis, data interpretation, writing of the report, or decision to submit the results. Competing interests: All authors have completed the ICMJE uniform disclosure form at www.icmje.org/coi_disclosure.pdf and declare: no support from any organisation for the submitted work; no financial relationships with any organisations that might have an interest in the submitted work in the previous three years; no other relationships or activities that could appear to have influenced the submitted work.

\section{Ethical approval: Not required.}

Data sharing: No additional data available.

1 Zoungas S, Patel A, Chalmers J, de Galan BE, Li Q, Billot L, et al. Severe hypoglycemia and risks of vascular events and death. N Engl J Med 2010;363:1410-8.

2 Duckworth WC, Abraira C, Moritz TE, Davis SN, Emanuele N, Goldman S, et al. The duration of diabetes affects the response to intensive glucose control in type 2 subjects: the VA Diabetes Trial. J Diabetes Complications 2011;25:355-61.

3 Kelly TN, Bazzano LA, Fonseca VA, Thethi TK, Reynolds K, He J. Systematic review: glucose control and cardiovascular disease in type 2 diabetes. Ann Intern Med 2009:151:394-403.

4 Boussageon R, Bejan-Angoulvant T, Saadatian-Elahi M, Lafont S, Bergeonneau C, Kassai $\mathrm{B}$, et al. Effect of intensive glucose lowering treatment on all cause mortality, cardiovascular death, and microvascular events in type 2 diabetes: meta-analysis of randomised controlled trials. BMJ 2011;343:d4169.

5 Gerstein HC, Miller ME, Byington RP, Goff DC Jr, Bigger JT, Buse JB, et al. Effects of intensive glucose lowering in type 2 diabetes. N Engl J Med 2008;358:2545-59.

6 Duckworth W, Abraira C, Moritz T, Reda D, Emanuele N, Reaven PD, et al. Glucose control and vascular complications in veterans with type 2 diabetes. N Engl J Med 2009;360:129-39.

7 Patel A, MacMahon S, Chalmers J, Neal B, Billot L, Woodward M, et al. Intensive blood glucose control and vascular outcomes in patients with type 2 diabetes. N Engl J Med 2008;358:2560-72.

8 Stratton IM, Adler Al, Neil HA, Matthews DR, Manley SE, Cull CA, et al. Association of glycaemia with macrovascular and microvascular complications of type 2 diabetes (UKPDS 35): prospective observational study. BMJ 2000;321:405-12.

9 Khaw KT, Wareham N, Bingham S, Luben R, Welch A, Day N. Association of hemoglobin A1c with cardiovascular disease and mortality in adults: the European prospective investigation into cancer in Norfolk. Ann Intern Med 2004:141:413-20.

10 Standl E, Balletshofer B, Dahl B, Weichenhain B, Stiegler H, Hormann A, et al. Predictors of 10-year macrovascular and overall mortality in patients with NIDDM: the Munich General Practitioner Project. Diabetologia 1996;39:1540-5.

11 Wright RJ, Frier BM. Vascular disease and diabetes: is hypoglycaemia an aggravating factor? Diabetes Metab Res Rev 2008:24:353-63.

12 Collier A, Patrick AW, Hepburn DA, Bell D, Jackson M, Dawes J, et al. Leucocyte mobilization and release of neutrophil elastase following acute insulin-induced hypoglycaemia in normal humans. Diabet Med 1990;7:506-9.

13 Jin WL, Azuma K, Mita T, Goto H, Kanazawa A, Shimizu T, et al. Repetitive hypoglycaemia increases serum adrenaline and induces monocyte adhesion to the endothelium in rat thoracic aorta. Diabetologia 2011;54:1921-9.

14 Desouza C, Salazar H, Cheong B, Murgo J, Fonseca V. Association of hypoglycemia and cardiac ischemia: a study based on continuous monitoring. Diabetes Care 2003;26:1485-9.

15 Adler GK, Bonyhay I, Failing H, Waring E, Dotson S, Freeman R. Antecedent hypoglycemia impairs autonomic cardiovascular function: implications for rigorous glycemic control. Diabetes 2009;58:360-6.

16 Stroup DF, Berlin JA, Morton SC, Olkin I, Williamson GD, Rennie D, et al. Meta-analysis of observational studies in epidemiology: a proposal for reporting. Meta-analysis $O$ Observational Studies in Epidemiology (MOOSE) group. JAMA 2000;283:2008-12.

17 Noto H, Goto A, Tsujimoto T, Noda M. Low-carbohydrate diets and all-cause mortality: a systematic review and meta-analysis of observational studies. PloS One 2013;8:e55030.

18 Noto H, Goto A, Tsujimoto T, Noda M. Cancer risk in diabetic patients treated with metformin: a systematic review and meta-analysis. PloS One 2012;7:e33411.

19 Van der Leeuw RM, Lombarts KM, Arah OA. Heineman MJ. A systematic review of the effects of residency training on patient outcomes. BMC Med 2012;10:65.

20 Noto H, Tsujimoto T, Sasazuki T, Noda M. Significantly increased risk of cancer in patients with diabetes mellitus: a systematic review and meta-analysis. Endocr Pract 2011;17:616-28 


\section{What is already known on this topic}

Earlier studies suggested a higher risk of cardiovascular disease in people with type 2 diabetes who experienced severe hypoglycaemia The association is, however, controversial and some researchers have proposed that severe hypoglycaemia is merely a marker of comorbid severe illness

Moreover, a systematic and quantitative summary of published studies is not available

\section{What this study adds}

Conventional meta-analysis suggests that severe hypoglycaemia is associated with a higher risk of cardiovascular disease Furthermore, a bias analysis indicates that comorbid severe illness alone may not entirely explain the positive association between severe hypoglycaemia and risk of cardiovascular disease

Avoiding severe hypoglycaemia may be important to prevent cardiovascular disease in people with type 2 diabetes

21 Noto H, Osame K, Sasazuki T, Noda M. Substantially increased risk of cancer in patients with diabetes mellitus: a systematic review and meta-analysis of epidemiologic evidence in Japan. J Diabetes Complications 2010;24:345-53.

22 Overeem K, Faber MJ, Arah OA, Elwyn G, Lombarts KM, Wollersheim HC, et al. Doctor performance assessment in daily practise: does it help doctors or not? A systematic review. Med Educ 2007;41:1039-49.

23 Greenland S, O'Rourke K. Meta-analysis. Modern epidemiology 3rd ed. Lippincott Williams \& Wilkins, 2008:652-82.

24 Johnston SS, Conner C, Aagren M, Smith DM, Bouchard J, Brett J. Evidence linking hypoglycemic events to an increased risk of acute cardiovascular events in patients with type 2 diabetes. Diabetes Care 2011;34:1164-70.

25 Zhao Y, Campbell CR, Fonseca V, Shi L. Impact of hypoglycemia associated with antihyperglycemic medications on vascular risks in veterans with type 2 diabetes. Diabetes Care 2012;35:1126-32.

26 Rathmann W, Kostev K, Gruenberger JB, Dworak M, Bader G, Giani G. Treatment persistence, hypoglycaemia and clinical outcomes in type 2 diabetes patients with dipeptidyl peptidase- 4 inhibitors and sulphonylureas: a primary care database analysis. Diabetes Obes Metab 2013;15:55-61

27 Hsu PF, Sung SH, Cheng HM, Yeh JS, Liu WL, Chan WL, et al. Association of clinical symptomatic hypoglycemia with cardiovascular events and total mortality in type 2 diabetes: a nationwide population-based study. Diabetes Care 2013;36:894-900.

28 Begg CB, Mazumdar M. Operating characteristics of a rank correlation test for publication bias. Biometrics 1994:50:1088-101.

29 Egger M, Davey Smith G, Schneider M, Minder C. Bias in meta-analysis detected by a simple, graphical test. BMJ 1997;315:629-34

30 DerSimonian R, Laird N. Meta-analysis in clinical trials. Control Clin Trials 1986;7:177-88.

31 Cochran W. The combination of estimates from different experiments. Biometrics 1954;10:101-29.

32 Higgins JP, Thompson SG, Deeks JJ, Altman DG. Measuring inconsistency in meta-analyses. BMJ 2003;327:557-60.

33 Arah OA, Chiba Y, Greenland S. Bias formulas for external adjustment and sensitivity analysis of unmeasured confounders. Ann Epidemiol 2008;18:637-46.

34 Lin DY, Psaty BM, Kronmal RA. Assessing the sensitivity of regression results to unmeasured confounders in observational studies. Biometrics 1998;54:948-63.

35 McCandless LC. Meta-analysis of observational studies with unmeasured confounders. Int J Biostat 2012;8:1-31.

36 Greenland S. Interval estimation by simulation as an alternative to and extension of confidence intervals. Int J Epidemiol 2004;33:1389-97.

37 Mellbin LG, Malmberg K, Waldenstrom A, Wedel H, Ryden L, DIGAMI 2 Investigstors. Prognostic implications of hypoglycaemic episodes during hospitalisation for myocardial infarction in patients with type 2 diabetes: a report from the DIGAMI 2 trial. Heart 2009;95:721-7.

38 Bonds DE, Miller ME, Bergenstal RM, Buse JB, Byington RP, Cutler JA, et al. The association between symptomatic, severe hypoglycaemia and mortality in type 2 diabetes: retrospective epidemiological analysis of the ACCORD study. BMJ 2010;340:b4909.
39 McCoy RG, Van Houten HK, Ziegenfuss JY, Shah ND, Wermers RA, Smith SA. Increased mortality of patients with diabetes reporting severe hypoglycemia. Diabetes Care 2012;35:1897-901.

40 Hsu PF, Sung SH, Yeh JS, Cheng HM, Chen WL, Chuang SY. The association between clinical symptomatic hypoglycemia with cardiovascular events in type 2 diabetes: a nested case control study in nation-wide representative population. Eur Heart $J$ 2012;33:180-1.

41 Zhao Y, Shi L, Fonseca V, Campbell CR. The impact of antidiabetic-induced hypoglycemia on clinical outcomes and resource utilization among veterans with type-2 diabetes mellitus (T2DM). Value Health 2011;14:A91.

42 Inzucchi SE, Bergenstal RM, Buse JB, Diamant M, Ferrannini E, Nauck M, et al. Management of hyperglycaemia in type 2 diabetes: a patient-centered approach. Position statement of the American Diabetes Association (ADA) and the European Association for the Study of Diabetes (EASD). Diabetologia 2012;55:1577-96.

43 Steenland K, Greenland S. Monte Carlo sensitivity analysis and Bayesian analysis of smoking as an unmeasured confounder in a study of silica and lung cancer. Am J Epidemiol 2004;160:384-92.

44 Gruden G, Barutta F, Chaturvedi N, Schalkwijk C, Stehouwer CD, Witte DR, et al. Severe hypoglycemia and cardiovascular disease incidence in type 1 diabetes: the EURODIAB Prospective Complications Study. Diabetes Care 2012;35:1598-604.

45 Ismail-Beigi F, Moghissi E, Tiktin M, Hirsch IB, Inzucchi SE, Genuth S. Individualizing glycemic targets in type 2 diabetes mellitus: implications of recent clinical trials. Ann Intern Med 2011:154:554-9.

46 UK Prospective Diabetes Study (UKPDS) Group. Effect of intensive blood-glucose control with metformin on complications in overweight patients with type 2 diabetes (UKPDS 34). Lancet 1998;352:854-65.

47 Bonds DE, Miller ME, Dudl J, Feinglos M, Ismail-Beigi F, Malozowski S, et al. Severe hypoglycemia symptoms, antecedent behaviors, immediate consequences and association with glycemia medication usage: Secondary analysis of the ACCORD clinical trial data. BMC Endocr Disord 2012;12:5.

48 Seaquist ER, Anderson J, Childs B, Cryer P, Dagogo-Jack S, Fish L, et al. Hypoglycemia and diabetes: a report of a workgroup of the American Diabetes Association and the Endocrine Society. Diabetes Care 2013;36:1384-95.

Accepted: 9 July 2013

\section{Cite this as: BMJ 2013;347:f4533}

This is an Open Access article distributed in accordance with the Creative Commons Attribution Non Commercial (CC BY-NC 3.0) license, which permits others to distribute, remix, adapt, build upon this work non-commercially, and license their derivative works on different terms, provided the original work is properly cited and the use is non-commercial. See: http://creativecommons.org/licenses/by-nc/3.0/. 


\section{Tables}

\section{Table 1 | Characteristics of studies included in meta-analysis}

Study (year of publication), location

ADVANCE (2010), Europe, Asia, Australia/New Zealand,

Canada $^{1}$

VADT (2011), USA
Johnston et al (2011), USA
Z4

Zhao et al (2012), USA ${ }^{25}$

Rathmann et al (2012), Germany ${ }^{26}$

Hsu et al (2012), Taiwan ${ }^{27}$

$58 \quad 66$

$66 \quad 5.0$ (median)

$97 \quad 60$

$51 \quad 61$

$60 \quad 5.6$ (median)

1.0 (mean)

3.9 (median)

672.0 (mean)

2.8 (mean)

2500

$\mathrm{NA}=$ not available. 


\begin{tabular}{|c|c|c|c|}
\hline Study & Exposure assessment & Outcome assessment & Adjustment for potential confounders \\
\hline ADVANCE $^{1}$ & $\begin{array}{l}\text { Hypoglycaemic episode that caused } \\
\text { transient dysfunction of central nervous } \\
\text { system and prevented patients from treating } \\
\text { themselves (requiring help from someone } \\
\text { else). } 231 \text { patients }(2.1 \% \text { ) experienced } \\
\text { severe hypoglycaemic episode }\end{array}$ & $\begin{array}{l}\text { Death from cardiovascular cause, non-fatal } \\
\text { myocardial infarction, or non-fatal stroke, which } \\
\text { were validated by independent adjudication } \\
\text { committee. Outcome occurred in } 35 \text { patients with } \\
\text { hypoglycaemic episode }(16.8 \%) \text { and } 1112 \text { without } \\
\text { hypoglycaemic episode }(10.2 \%)\end{array}$ & $\begin{array}{l}\text { Age, sex, treatment assignment, duration of diabetes, } \\
\text { history of macrovascular or microvascular } \\
\text { complications, smoking status at baseline, and time } \\
\text { dependent covariates during follow-up (age, glycated } \\
\text { haemoglobin }\left(\mathrm{HbA}_{1 \mathrm{c}}\right) \text {, body mass index, creatinine } \\
\text { levels, ratio of urinary albumin to creatinine, systolic } \\
\text { blood pressure, and use of antihyperglycaemic agents } \\
\text { or antihypertensive agents) }\end{array}$ \\
\hline $\mathrm{VADT}^{2}$ & $\begin{array}{l}\text { Hypoglycaemic episode within previous } \\
\text { three months that was life threatening or } \\
\text { fatal, caused disability or incapacity, or } \\
\text { required admission to hospital or medical } \\
\text { intervention. } 104 \text { patients (5.8\%) } \\
\text { experienced severe hypoglycaemic episode }\end{array}$ & $\begin{array}{l}\text { Myocardial infarction, cardiovascular death, } \\
\text { cardiovascular accident, amputation due to } \\
\text { ischaemia, surgical intervention for vascular } \\
\text { disease, new or worsening congestive heart } \\
\text { failure, stroke, and inoperable coronary artery } \\
\text { disease that were adjudicated by an endpoints } \\
\text { committee. Outcome occurred in } 499 \text { patients } \\
(27.9 \%)\end{array}$ & $\begin{array}{l}\text { Age, treatment assignment, duration of diabetes, } \\
\text { previous cardiovascular event, insulin use, race, } \\
\text { smoking status, and glycated haemoglobin }\left(\mathrm{HbA}_{10}\right) \text { at } \\
\text { baseline. Time dependent covariates during follow-up } \\
\text { included total cholesterol, high density lipoprotein } \\
\text { cholesterol, and creatinine levels }\end{array}$ \\
\hline $\begin{array}{l}\text { Johnston et } \\
\mathrm{al}^{24}\end{array}$ & $\begin{array}{l}\text { Hypoglycaemic episode identified by } \\
\text { diagnosis of hypoglycaemia (ICD-9-CM } \\
\text { codes } 251.0,251.1,251.2 \text {, and } 250.8 \text { ) using } \\
\text { healthcare claims. } 27065 \text { patients ( } 3.1 \% \text { ) } \\
\text { experienced hypoglycaemic episode }\end{array}$ & $\begin{array}{l}\text { ICD-9-CM coded coronary artery bypass graft, } \\
\text { revascularisation, percutaneous coronary } \\
\text { intervention, acute myocardial infarction, or } \\
\text { incidence of unstable angina, identified by } \\
\text { healthcare claims. Outcome occurred in } 5.3 \% \text { of } \\
\text { patients with hypoglycaemic episode and } 2.2 \% \\
\text { without hypoglycaemic episode }\end{array}$ & $\begin{array}{l}\text { Age, sex, location of residence, insurance type, } \\
\text { Charlson comorbidity index, Agency for Healthcare } \\
\text { and Research Quality comorbidity index, } \\
\text { hypercholesterolaemia, hypertension, peripheral } \\
\text { vascular disease, chronic kidney disease, baseline } \\
\text { microvascular complications, baseline medical } \\
\text { expenditures, number of medical encounters with } \\
\text { diagnosis of diabetes, previous cardiovascular disease, } \\
\text { and use of antihyperglycaemic, antiplatelet, } \\
\text { antihypertensive, or anticoagulant agents }\end{array}$ \\
\hline Zhao et $\mathrm{al}^{25}$ & $\begin{array}{l}\text { Hypoglycaemic episode identified by } \\
\text { diagnosis of hypoglycaemia (ICD-9-CM } \\
\text { codes } 251.0,251.1,251.2 \text {, and } 250.8 \text { ) using } \\
\text { data from electronic medical records. } 761 \\
\text { patients (1.7\%) experienced hypoglycaemic } \\
\text { episode }\end{array}$ & $\begin{array}{l}\text { ICD-9-CM coded myocardial infarction, stroke, } \\
\text { congestive heart failure, and peripheral vascular } \\
\text { disease identified by data from electronic medical } \\
\text { records. Outcome occurred in } 30.65 \% \text { patients } \\
\text { with hypoglycaemic episode and } 17.48 \% \text { without } \\
\text { hypoglycaemic episode }\end{array}$ & $\begin{array}{l}\text { Age, sex, race, marital status, body mass index, } \\
\text { insurance, renal disease, mental disorder, substance } \\
\text { misuse, tobacco use, Charlson comorbidity index, and } \\
\text { use of antihyperglycaemic agents, antihypertensive } \\
\text { agents, or statins }\end{array}$ \\
\hline $\begin{array}{l}\text { Rathmann } \\
\text { et } \mathrm{al}^{26}\end{array}$ & $\begin{array}{l}\text { Hypoglycaemic episode identified by } \\
\text { diagnosis of hypoglycaemia (ICD-10 codes } \\
\text { E16.0, E16.1 and E16.2) using primary care } \\
\text { databases. Hypoglycaemic episode } \\
\text { documented in } 0.7 \% \text { of patients }\end{array}$ & $\begin{array}{l}\text { ICD-10 coded coronary heart disease, myocardial } \\
\text { infarction, stroke, and peripheral vascular disease, } \\
\text { identified by data from primary care databases. } \\
\text { Outcome occurred in } 12.5 \% \text { of patients }\end{array}$ & $\begin{array}{l}\text { Age, sex, location of residence, insurance type, } \\
\text { practice (diabetologist), Charlson comorbidity index, } \\
\text { hyperlipidaemia, hypertension, baseline microvascular } \\
\text { complications, and use of antihyperglycaemic, } \\
\text { antihypertensive, lipid lowering, or antithrombotic } \\
\text { agents }\end{array}$ \\
\hline Hsu et $\mathrm{al}^{27}$ & $\begin{array}{l}\text { Hypoglycaemic episode identified by } \\
\text { diagnosis of hypoglycaemia (ICD-9-CM } \\
\text { codes } 251.2 \times \text { ) using inpatient claims. } \\
\text { Hypoglycaemic episode documented in } \\
0.6 \% \text { of patients }\end{array}$ & $\begin{array}{l}\text { ICD-9-CM coded cardiovascular diseases } \\
\text { (ICD-9-CM codes } 390 \text { to } 459 \text { ) from hospital claim } \\
\text { dataset. Outcome occurred in } 106 / 1000 \text { person } \\
\text { years in patients without hypoglycaemic episode } \\
\text { and } 324 / 1000 \text { person years in patients with } \\
\text { hypoglycaemic episode }\end{array}$ & $\begin{array}{l}\text { Age, sex, duration of diabetes, dyslipidaemia, } \\
\text { hypertension, atrial fibrillation, liver cirrhosis, renal } \\
\text { disease, mental disease, previous cancer, previous } \\
\text { stroke, previous heart disease, high social economic } \\
\text { status, good compliance, and use of } \\
\text { antihyperglycaemic agents }\end{array}$ \\
\hline
\end{tabular}


Table 3| Stratified analysis of severe hypoglycaemia and risk of cardiovascular disease

\begin{tabular}{|c|c|c|c|c|c|}
\hline Group & No of studies & Relative risk $^{*}(95 \% \mathrm{Cl})$ & P for heterogeneity $\dagger$ & $I^{2}(\%)$ & P for interaction $\neq$ \\
\hline Total & 6 & 2.05 (1.74 to 2.42$)$ & 0.002 & 73.1 & \\
\hline \multicolumn{6}{|l|}{ Design: } \\
\hline Prospective & 2 & $2.67(1.48$ to 4.80$)$ & 0.10 & 63.8 & \multirow[t]{2}{*}{0.29} \\
\hline Retrospective & 4 & 1.93 (1.68 to 2.21$)$ & 0.03 & 65.4 & \\
\hline \multicolumn{6}{|l|}{ Study location: } \\
\hline USA & 3 & $1.81(1.71$ to 1.90$)$ & 0.58 & 0.0 & \multirow[t]{2}{*}{0.18} \\
\hline Non-USA & 3 & 2.29 (1.62 to 3.24$)$ & 0.02 & 76.2 & \\
\hline \multicolumn{6}{|l|}{ Sex: } \\
\hline Men $(>95 \%)$ & 2 & 1.99 (1.64 to 2.41$)$ & 0.85 & 0 & \multirow[t]{2}{*}{0.71} \\
\hline Both & 4 & 2.10 (1.67 to 2.65$)$ & $<0.001$ & 83.4 & \\
\hline \multicolumn{6}{|c|}{ Follow-up (years): } \\
\hline$>1$ & 5 & 2.16 (1.77 to 2.64$)$ & 0.048 & 58.2 & \multirow[t]{2}{*}{0.07} \\
\hline$\leq 1$ & 1 & 1.79 (1.69 to 1.89$)$ & - & - & \\
\hline \multicolumn{6}{|l|}{ Insulin users: } \\
\hline Included & 5 & 2.13 (1.77 to 2.57$)$ & 0.001 & 77.6 & \multirow[t]{2}{*}{0.15} \\
\hline Excluded & 1 & $1.60(1.13$ to 2.26$)$ & - & - & \\
\hline \multicolumn{6}{|c|}{ Adjustment for race and dyslipidaemia: } \\
\hline Yes & 5 & $1.93(1.70$ to 2.18$)$ & 0.07 & 53.9 & \multirow[t]{2}{*}{0.005} \\
\hline No & 1 & 3.45 (2.34 to 5.08$)$ & - & - & \\
\hline \multicolumn{6}{|c|}{ Adjustment for smoking status: } \\
\hline Yes & 3 & 2.37 (1.61 to 3.47$)$ & 0.043 & 68.2 & \multirow[t]{2}{*}{0.32} \\
\hline No & 3 & 1.91 (1.59 to 2.29$)$ & 0.02 & 75.0 & \\
\hline \multicolumn{6}{|c|}{ Adjustment for body mass index: } \\
\hline Yes & 2 & 2.56 (1.50 to 4.36$)$ & 0.01 & 83.3 & \multirow[t]{2}{*}{0.30} \\
\hline No & 4 & 1.91 (1.62 to 2.34$)$ & 0.046 & 62.5 & \\
\hline
\end{tabular}

*Relative risk estimates obtained using conventional random effects model.

†P values for heterogeneity across studies computed using Cochrane's $Q$ test.

$\ddagger P$ values for comparisons between subgroups computed using $x^{2}$ test with 1 degree of freedom. 


\section{Figures}

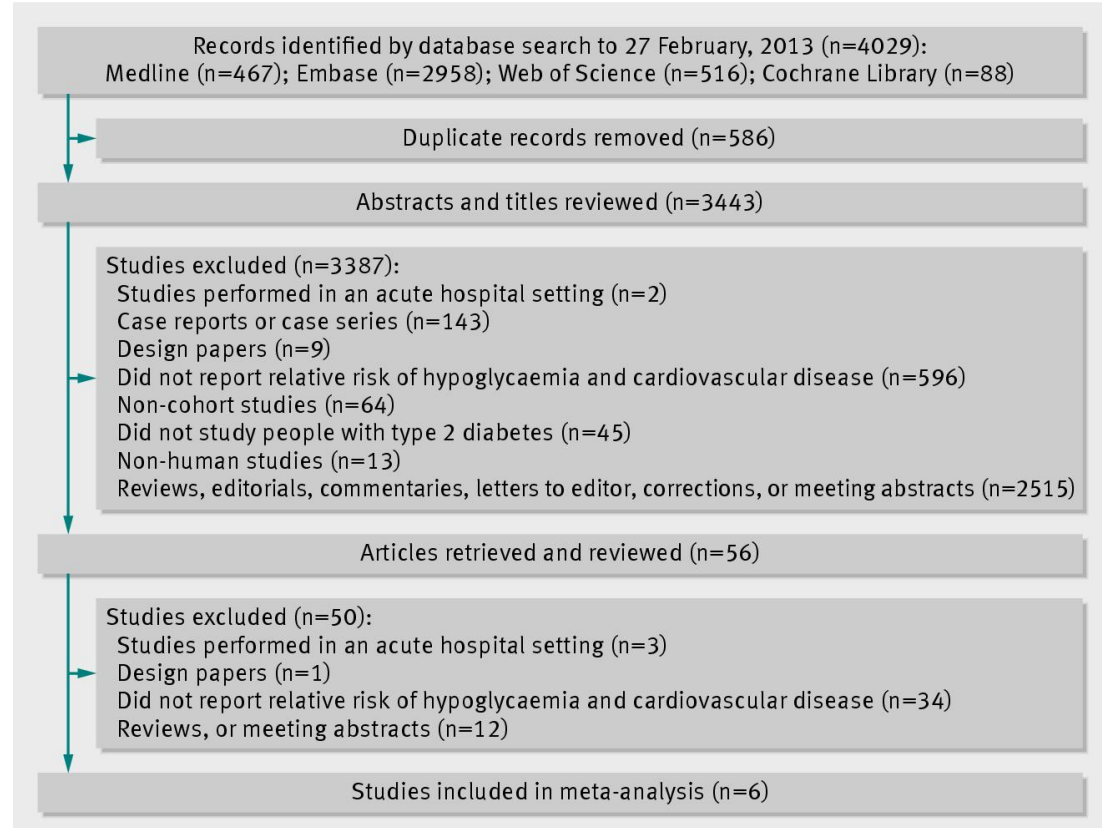

Fig 1 Flow of studies through review

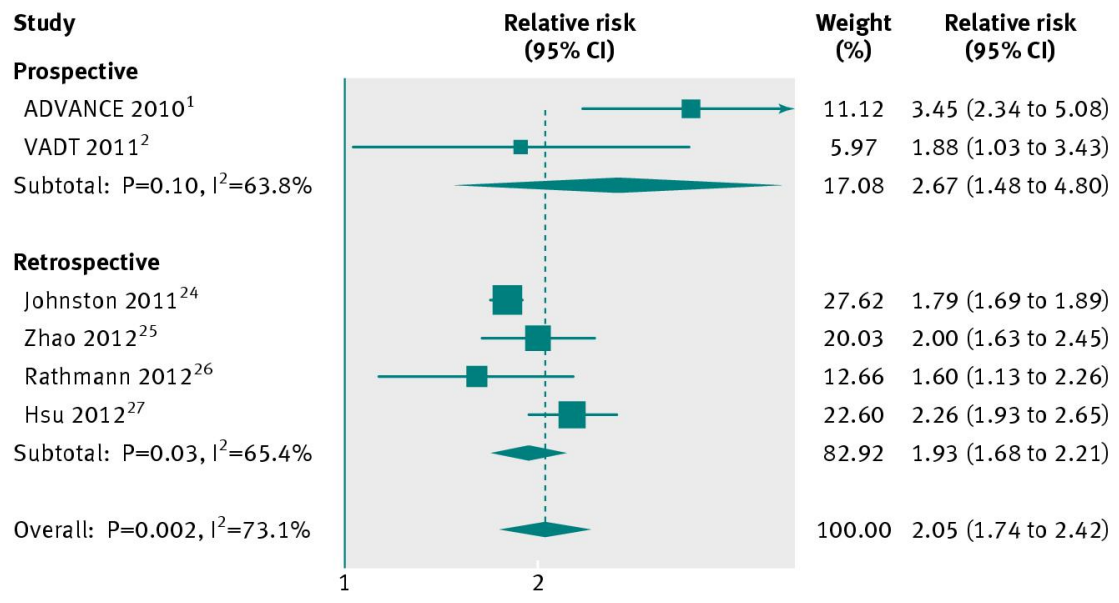

Fig 2 Conventional random effects meta-analysis according to study design. ADVANCE=Action in Diabetes and Vascular Disease: Preterax and Diamicron Modified Release Controlled Evaluation; VADT=Veterans Affairs Diabetes Trial. Dots indicate relative risks for severe hypoglycaemia and cardiovascular events in people with type 2 diabetes. Horizontal lines indicate $95 \%$ confidence intervals for relative risks. Diamonds represent pooled relative risk estimates with $95 \%$ confidence intervals 
Prevalence of comorbid severe illness in patients with severe hypoglycaemia (\%)

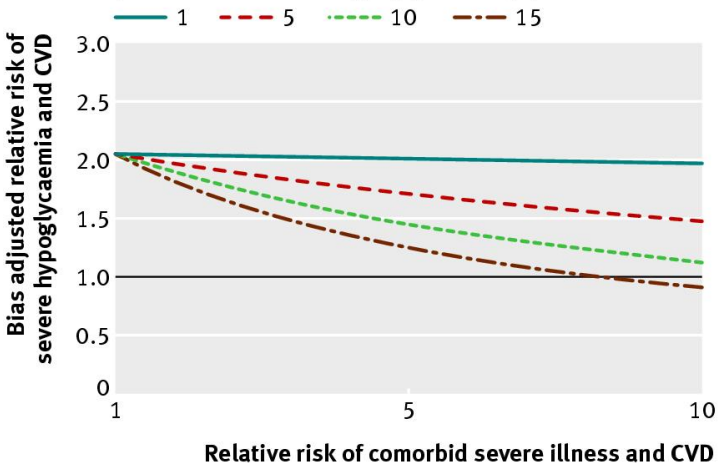

Fig 3 Random effects meta-analysis with bias analysis. Bias adjusted relative risks of severe hypoglycaemia and cardiovascular disease were computed to examine the sensitivity of the association to possible confounding by comorbid severe illness. The prevalence of comorbid severe illness in patients without severe hypoglycaemia was assumed to be $0.5 \%$. CVD=cardiovascular disease 